\title{
An experimental study on performace of starch extracted from wheat flour as filtration control agent in drilling fluid
}

\author{
Raheel Iqbal, Fawad Pirzada, Muhammad Zubair, Ameer Mehmood \\ Institute of Petroleum \& Natural Gas, Mehran University of Engineering \& Technology, Pakistan
}

\begin{tabular}{l} 
Article Info \\
\hline Article history: \\
Received Dec 23, 2019 \\
Revised Feb 2, 2020 \\
Accepted Jun 5, 2020 \\
\hline
\end{tabular}

\section{Keywords:}

Drilling fluid

Filtration control

Fluid loss

Rheological properties

Wheat flour

\begin{abstract}
The phenomenon of lost of mud filtrate into a porous permeable formation due to high hydrostatic pressure compared to the formation pressure is known as fluid loss. This cause some major problems in well during drilling as poor cementing job, pipe stuck, and formation damage. Thus, to safe the well from such problems and in order to make safe and effective drilling an additive from wheat flour is extracted which is starch, and acting as a fluid loss control agent. The purpose of this research is to investigate the potential of utilizing this additive to form environmentally safe, non-toxic, high biodegradability and low-cost water-based drilling fluid samples with varying the amount of starch. Experimental results showed that Efficiency of starch obtained from wheat-flour is showing increment in rheological properties as compare to starch present in market by using same and varying quantity of both and observed that wheat-flour starch is more efficient as compare to starch in market. On the other hand, the efficiency of starch is good but it has been also improved by the extraction of starch from wheatflour by the centrifugation process.
\end{abstract}

This is an open access article under the CC BY-SA license.

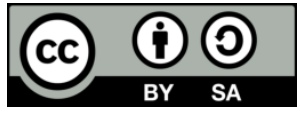

\section{Corresponding Author:}

Raheel Iqbal,

Institute of Petroleum \& Natural Gas Engineering,

Mehran University of Engineering \& Technology,

Indus Hwy, Jamshoro, Sindh 76062, Pakistan.

Email: 15PG46@students.muet.edu.pk | raheelarain66@gmail.com

\section{INTRODUCTION}

The Drilling fluid has the obligatory properties like carrying out rock cutting towards the surface, cleaning \& cooling the bit, decreasing resistive forces, stabilizing wellbore \& to prevent fluids that flow from pores into the borehole. The various methods for designing suitable drilling muds are developed for avoiding complexity of problems encountered during drilling operation. Since the initial operations that were executed in USA (which consist of clays and water for use) to complicated blends of distinct particular natural \&artificial materials which are currently used. The drilling mud should be user friendly, cost effective and economically viable. Therefore, drilling muds are basically formulated to decrease the effect of damage and to ensure the possibility and economically viability of rotary drilling in hydrocarbon containing formations. The filter cakes which are formed after the intrusion of drilling mud in the pore space of pay zone are compressible and they contain variable porosity and permeability characteristics, with low void spaces at the filter channel surface and maximum void spaces on cake surface [1]. In order to reduce filtrate invasion, fluid loss additives such as organic polymers are used which prohibit water invasion into formation. During the formulation of a mud in addition to microscopic structure and composition of filter cake related to it and the information of the characteristics of filtration, are of main importance [2]. During drilling and completion varying drilling muds in the bore-hole are used. The most significant factor for the increasing the production 
is the physical and chemical compatibility of the mud with the reservoir rock. By the formation damage these muds can reduce the productivity of the well by invasion. Consequently, those additives are used i.e. $\mathrm{CaCO} 3$, which can reduce the chances of these damages in the formations by forming a filter cake of low permeability (optimum thickness) that reduces further invasion of solids and filtrate in the pore spaces of rock. After drilling these cakes are washed by for maximizing the flow in the wellbore [3].

Fluid loss and viscosity of mud are the important factors which must be investigated throughout the drilling of a well. For that mud is treated with several types of additives i.e. different polymers and chemicals, to achieve the requirements important for the particular well such as rheology, control of fluid loss, and weight of mud etc. Starch and calcite are the most important materials used to control fluid loss and to increase the weight of mud by forming mud cake respectively [4].

\section{RESEARCH METHOD}

\subsection{Drilling fluid preparation and properties}

Few of the additives along with Barite $\mathrm{BaSO}_{4}$ and $\mathrm{Calcite} \mathrm{CaCO}_{3}$ are most commonly used in waterbased drilling mud. Mainly three main factors which influenced the performance of drilling fluid are i.e., density, viscosity and filtration of drilling fluid. Therefore, more consideration for these factors during experimental work for the preparation of water-based fluid samples should be paid [4].

The fluid samples preparation at laboratory scale is obtained by the applying this methodology that any material of $1 \mathrm{~g}$ added to a $350 \mathrm{ml}$ laboratory barrel at the standard level, that is relevant to addition of 1 pound of material to a fluid of 1 barrel.

This study is involved the preparation of four water-based drilling fluid samples which contain Bentonite as a filtration controller and viscosifier, for $\mathrm{pH}$ control caustic soda is used, and barite is used as a weighting agent. Along with them soda ash and Xanthan gum are also used as a hardness and rheology control materials respectively. The composition of all these additives is constant for all prepared samples except starch.

Then the most important is the concentration of starch as a filtration control agent is used to prepare samples of densities of 10.5 PPG. One of the samples labeled as sample no.1 is based on pure starch and the rest of the three samples are based on starch extracted from wheat-flour with varying amount as the compositions of prepared samples shown in Table 1.

Table 1. Drilling mud samples composition

\begin{tabular}{lcccc} 
& \multicolumn{4}{c}{ Per lab barrel (350 ml) } \\
& Product & \multicolumn{4}{c}{ Sample number } \\
& 1 & 2 & 3 & 4 \\
\hline Water (ml) & 325.5 & 325.5 & 325.5 & 325.5 \\
Bentonite (g) & 24.5 & 24.5 & 24.5 & 24.5 \\
Barite (g) & 101 & 101 & 101 & 101 \\
$\mathrm{CaCO}_{3}$ & - & - & - & - \\
Starch (pure) (g) & 0.40 & - & - & - \\
Starch (Wheat-Flour) (g) & - & 0.40 & 0.35 & 0.45 \\
Caustic Soda (g) & 0.20 & 0.20 & 0.20 & 0.20 \\
Soda Ash (g) & 0.25 & 0.25 & 0.25 & 0.25 \\
Xanthan Gum (g) & 1.00 & 1.00 & 1.00 & 1.00 \\
\hline
\end{tabular}

\subsection{Density of mud}

Density of the mud is the main parameter to consider during study and before the drilling process as it directly affects the properties of filter cake i.e. damage to the formation and filtrate loss.

An apparatus named as mud balance is used to choose such weight of mud in ppg that cause ceramic disk to less damage. The most common additive to increase the weight of mud in production zones is mostly calcite $\left(\mathrm{CaCO}_{3}\right)$ and barite $\left(\mathrm{BaSO}_{4}\right)$ to a less extent used in drilling fluids in hydrocarbon industries [5].

Four drilling mud samples by formulating both starches are prepared in this study to achieve the density range of $10.5 \mathrm{ppg}$. The amount use for the formulation of pure starch-based sample is $0.40 \mathrm{~g}$, and the amount for the formulation of wheat-flour based samples ranges from $0.35-0.45 \mathrm{~g}$.

\subsection{Drilling fluid rheological properties}

The flow of matter or the fluids deformation is involved in the study of rheology. The importance of rheology is acknowledged during the fluid flow (velocity profiles) analysis, viscosities of fluids (apparent, plastic, and marsh funnel viscosities), cleaning the annular borehole and the losses of friction pressure. 
The basis for all the investigations including hydraulics of wellbore and to evaluate the mud system functionality is the rheological properties. Gel strength and yield points of the fluids are also included in rheological properties. Mud rheological properties i.e. Gel, viscosities, yield point, and density are continuously tested throughout the operation of drilling a well. Mud rheological properties are very critical to maintain and control during the failure due to result in time, financial loss, and in excessive cases, the result is in the abandonment of the well. Filtration, $\mathrm{pH}$, chemical analysis (alkalinity and lime content, chloride, calcium, etc.), and resistivity apart from rheology are also tested throughout the drilling of a well [6].

In drilling fluid laboratories as well as on rig site, rotational viscometer is frequently used to measure the rheological properties of mud.

The readings are taken on 600, 300, 200, 100, 60, 30 and $6 \mathrm{rpm}$ (rotation per minute). Later these readings are plotted on a chart of shear stress and shear rate which are used to determine viscosity and appropriate viscosity model.

Rotational viscometer also provides the information about other rheological properties, which include apparent, plastic, and effective viscosities ( $\mu \mathrm{a}, \mu \mathrm{p}$, and $\mu \mathrm{e})$, gel strength (Gel) and yield point (YP) as shown in Table 2.

Table 2. Rheological properties of mud sample

\begin{tabular}{lcccc}
\hline \multicolumn{1}{c}{ Sample Number } & 1 & 2 & 3 & 4 \\
\hline Plastic Viscosity (cp) & 18 & 25 & 27 & 24.5 \\
Apparent Viscosity (cp) & 32.75 & 40 & 37.5 & 42 \\
Yield Point (Ib/100 ft $\left.{ }^{2}\right)$ & 29.5 & 30 & 21 & 35 \\
Gel Strength @ $10 \mathrm{~min}\left(\mathrm{Ib} / 100 \mathrm{ft}^{2}\right)$ & 15 & 17.3 & 15.50 & 19.25 \\
$\emptyset_{600}$ & 65.5 & 80 & 75 & 84 \\
$\emptyset_{300}$ & 47.5 & 55 & 48 & 59.5 \\
$\emptyset_{200}$ & 40 & 46 & 40.50 & 50.25 \\
$\emptyset_{100}$ & 31 & 35.5 & 32 & 39 \\
$\emptyset_{60}$ & 27 & 30 & 27.50 & 34 \\
$\emptyset_{30}$ & 23 & 25 & 23.50 & 27 \\
$\emptyset_{6}$ & 17 & 19 & 17 & 20 \\
\hline
\end{tabular}

Given equations are utilized for these purposes:

$$
\begin{aligned}
& \text { Apparent Viscosity }\left(\mu_{\mathrm{a}}\right),(\mathrm{cp})=\frac{\emptyset 600}{2} \\
& \text { Plastic Viscosity }\left(\mu_{\mathrm{p}}\right),(\mathrm{cp})=\emptyset_{600}-\emptyset_{300} \\
& \text { Effective Viscosity }\left(\mu_{\mathrm{e}}\right),(\mathrm{cp})=\frac{300 x \emptyset}{\omega} \\
& \text { Yield Point }(\mathrm{Yp}),\left(\mathrm{lb} / 100 \mathrm{ft}^{2}\right)=\emptyset 300-\mu_{p} \\
& \text { Shear Stress }(\tau),\left(\mathrm{lb} / 100 \mathrm{ft}^{2}\right)=1.065 * \emptyset \\
& \text { Shear Rate }(\mathrm{\gamma}), \mathrm{sec}-1=1.7023 * \omega
\end{aligned}
$$

Where, $\varnothing$ indicates the reading of dial, $\mathrm{lb} / 100 \mathrm{ft} 2$ and $\omega$ indicates rotation of rotor speed, $\mathrm{rpm}$.

\subsection{Bingham plastic fluid}

To identify the properties related to flow for the different mud types Bingham plastic model is a basic two-parameter model used in drilling industry widely. It is known to as most common model for fluid to estimate the non-Newtonian fluids rheology. Shear stress is a straight-line function of shear rate which is the basic supposition of this model. Yield point or also named as threshold stress is the point where shear rate is zero. By the reduction in colloidal solids plastic viscosity (PV) is achieved best and as low as possible for drilling fast.

While, to carry cuttings out of the hole, yield point (YP) should be high enough, but not as much that pressure of pump would be unwanted when flow of mud initiated. On the behalf of treatment for mud adjustments in YP is done. For the both low and high shear rates range Bingham plastic model have its own limitations. The physical/solid reason behind this behaviour is that the liquid generally contains particles (clay) or large molecules (polymers) which generally have some kind of interaction, while creating a weak 
solid structure, formerly known as a false body, and at that point a certain amount of stress is required to break this structure. Under viscous forces the particles tend to move as the once that structure has been broken. Again, the particles are linked, by removing that stress [7].

Those results which are acceptable for a drilling mud diagnosis are produced by Bingham plastic model. But, for hydraulic calculations its accuracy is not that much. A Bingham body doesn't begin to flow until a shearing stress, corresponding to the yield value, is exceeded. The results for Bingham Plastic Model are obtained by plotting graph between shear stress and shear rate as shown in Figure 1, which are calculated by using the shear stress and shear rate (5) and (6).

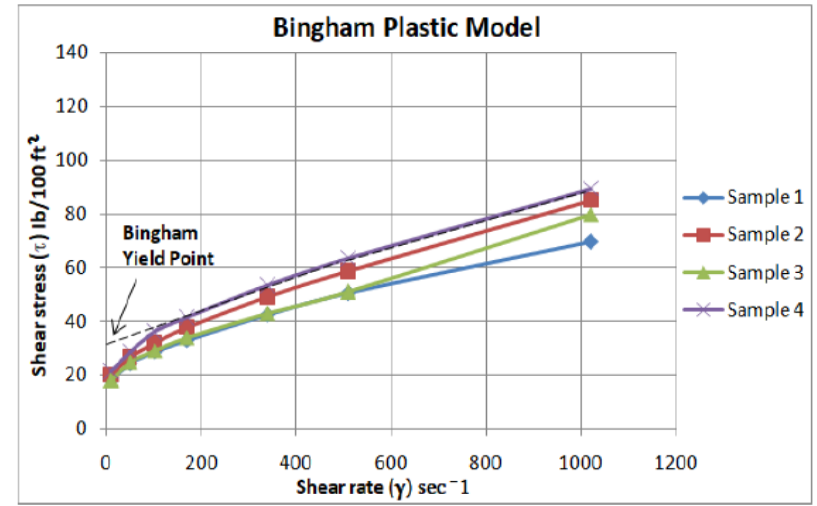

Figure 1. Bingham plastic model of samples

\subsection{Drilling fluid ph determination}

The importance of $\mathrm{pH}$ is cleared by knowing this that it affects the solubility of the organic thinners, contaminant removal, corrosion mitigation and the dispersion of clays presents in the mud. For hydrogen ion concentration representation of a mud the vital role is played by $\mathrm{pH} . \mathrm{pH}$ is mostly used to express the drilling fluid especially water- based mud acidity or alkalinity. Generally, a numerical value ranges from $0-14$ are used for the representation of $\mathrm{pH}$ of any fluid which indicates that the hydrogen concentration in the fluid is an inverse measurement [4].

$\mathrm{pH}$ is expressed by the equation given follow:

$\mathrm{pH}=-\log 10[\mathrm{H}]$

Where, $\mathrm{H}$ is the hydrogen ion concentration in mol.

The $\mathrm{pH}$ value decreases according to the formulae as the acidity of the fluid increases by the addition of more hydrogen atoms. Generally, $\mathrm{pH}$ of the fluid is considered at 7 . Above the reading 7 indicates the alkaline $\mathrm{pH}$ of any of the fluid. And the $\mathrm{pH}$ below 7 referred to acidic $\mathrm{pH}$. In drilling mud there are main three chemical components involved which are $\left(\mathrm{OH}^{-}\right)$hydroxyl ions, carbonate ions $\left(\mathrm{CO}_{3}^{-2}\right)$ and alkalinity of drilling mud including $\left(\mathrm{HCO}^{-}\right)$bicarbonates ions [8].

The acidity reduced by ions are represented and known as the alkalinity. So for the better measurement of $\mathrm{pH}$, it is observed that $\mathrm{pH}$ meter is mostly used rather than the of a $\mathrm{pH}$ paper because of that $\mathrm{pH}$ meter measured the accurate figures values. However, it is ensured that the $\mathrm{pH}$ meter is calibrated accurately.

\section{RESULTS AND DISCUSSIONS}

\subsection{Characteristics of drilling fluids}

Achieved drilling fluid samples densities of four samples of both starch's based are 10.5 PPG as shown in Figure 2. Prepared four samples of mud with rheological properties which are obtained in this study based on different filtration controllers are shown in Table 2. 


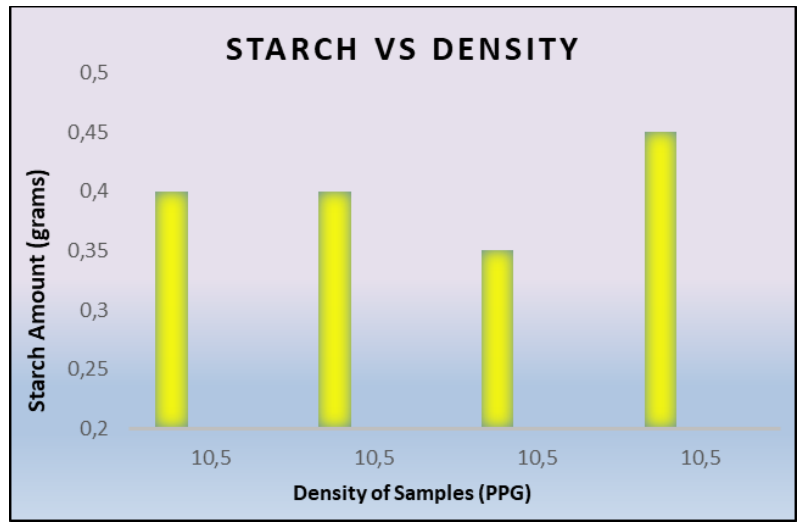

Figure 2. Amount of starch vs densities

After an accurate look to the measured values of prepared samples, the observations are that the prepared drilling fluid samples rheological properties based on different filtration control agents are showing the variation in obtained results such as plastic viscosity, apparent viscosity, yield point, and gel strength of all samples are different. But it is observed that sample no. 2 with amount of $0.40 \mathrm{~g}$ of starch from wheat- flour when compared with the sample no. 1 with amount of $0.40 \mathrm{~g}$ of pure starch, all the obtained results of wheat-flour based starch sample is showing better apparent and plastic viscosities including good yield point and gel strength as shown in Table 2 .

\subsection{Bingham plastic model}

It is discussed that fluids which are non-Newtonian exhibit a relationship between the shear rate and shear stress measured for the formulated samples as shown in Figure 1.

According to the graphs which are plotted for four water- based drilling fluid samples representing that the fluid samples of $10.5 \mathrm{ppg}$ are showing almost varying trend except sample no. 1 and sample no. 3 which are same at some extent and then variation occurred also between them as shown in Figure 1.

A general trend line is drawn for the Bingham plastic fluid and it is observed that the two different filtration control fluid samples exhibit much higher shear stress and a yield point of $35 \mathrm{Ib} / 100 \mathrm{ft} 2$ is obtained as line cutting the vertical axis as shown in Figure 1. For wheat flour starch-based sample no. 4 and it is also discussed in Table 2 as compare to the pure starch-based sample no. 1 and other samples of wheat-flour starch.

\section{3. $\mathbf{p H}$ determination}

$\mathrm{pH}$ of the prepared sample is determined by using $\mathrm{pH}$ meter and the obtained results are listed as shown in Figure 3. If a comparison is generated between both starch-based samples which include pure starch and starch from wheat-flour, it is observed that there is a difference between $\mathrm{pH}$ of all samples. But it is also observed that the sample no. 1 which contains pure starch with amount of $0.40 \mathrm{~g}$ is showing a $\mathrm{pH}$ value almost similar to the sample no. 3 with amount of 0.35 which is based on wheat-flour starch as shown in Figure. 3.

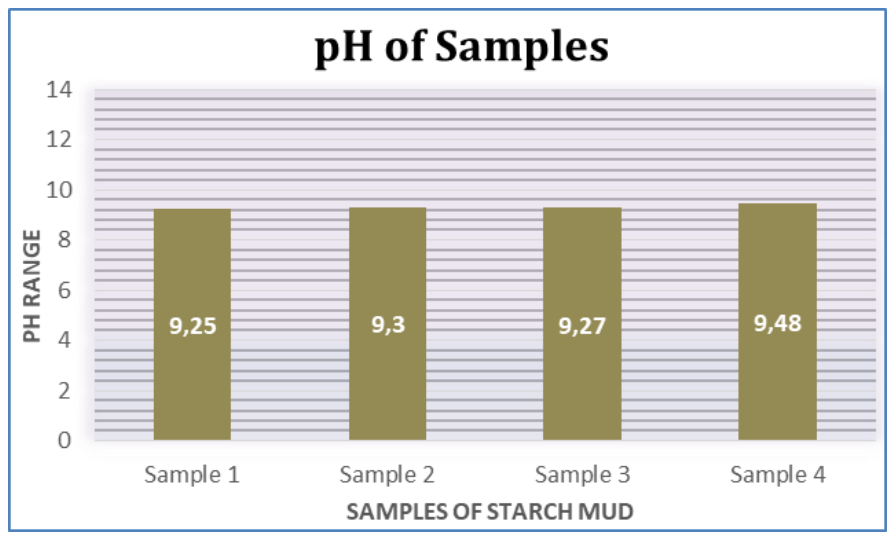

Figure 1. pH of mud samples 
Though, it is also observed that wheat-flour starch is efficient in $\mathrm{pH}$ study, because of the reason that sample no. 1 contains amount of starch $0.40 \mathrm{~g}$ and $\mathrm{pH}$ value 9.25, and at the same time sample no.3 contain amount of starch $0.35 \mathrm{~g}$ and $\mathrm{pH}$ value 9.27 .

\section{CONCLUSION}

As this study is related the investigation about the effect and efficiency of starch derived from wheat flour to prepare the samples of water-based drilling fluid and compare their results with the samples which are prepared by using same composition of starch present in market and used in industry. On the basis of laboratory measurements analysis and interpretation, the main concluded and recommended points are listed:

- $\quad$ Mud weight of $10.5 \mathrm{lb} / \mathrm{gal}$ which is optimum for the $\mathrm{X}$ well was selected among the five prepared mud densities, considering that it can sustain the formation pressure. By using another mud weight the formation starts to create fractures in the well by the effect of mud weight density.

- Efficiency of starch obtained from wheat-flour is showing increment in rheological properties as compare to starch present in market by using same and varying quantity of both and observed that wheat-flour starch is more efficient as compare to starch in market.

- On the other hand, the efficiency of starch is good but it will be also improved by the extraction of starch from wheat-flour by the centrifugation process.

- It is also concluded that less the amount of wheat flour starch in drilling fluid then higher will be the $\mathrm{pH}$ value.

\section{ACKNOWLEDGEMENTS}

We would like to acknowledge institute of Petroleum \& Natural Gas Engineering of Mehran UET Jamshoro for their incredible support in our research.

\section{REFERENCES}

[1] Khaled J. Hassiba \& Mahmood Amani, "The effect of salinity on the rheological properties of waterbased mud under high pressures and high temperatures for drilling offshore and deep wells," Earth Science Research, vol. 2, no. 1, 2013.

[2] Khaled Elshreef \& Aref Lashin,"Investigation of mud density and weighting materials effect on drilling fluid filter cake properties and formation damage,"Journal of African Earth Sciences, Feb 2016.

[3] Prasenjit Talukdar and Subrata Borgohain Gogoi, "Use of Calcium Carbonate as bridging and weighting agent in the non-damaging drilling fluid for some oilfields of Upper Assam Basin," International Journal of Current Research, vol. 7, no. 08, pp.18964-18981, Aug2015.

[4] Hudson, T. \& Coffey, M. "Fluid loss control through the use of a liquid thickened completion and work over brine," Journal of Petroleum Technology, vol. 35, no. 10, pp. 1776-1782, 1983.

[5] Majid Sajjadian, Ehsan Esmaeil pour Motlagh, Ali Akbar Daya, "Laboratory investigation to use lost circulation material in water base drilling fluid as lost circulation pills, “ International Journal of Mining Science (IJMS), vol 2, no. 1, pp. 33-38, 2016.

[6] Nediljka Gaurina-Medimurec, "Laboratory Evaluation of Calcium Carbonate particle size selection for drill-in fluids," Rudarsko-gcolofko-naftnizbomik, vol. 14, no. 14, 2002.

[7] Aydin Od abasi, "An experimental study of particle size and concentration effects of Calcium Carbonate on Rheological and Filtration properties of drill-in fluids," In partial fulfillment of the requirements for the degree of Master of Science in Petroleum and Natural Gas Engineering Department Middle East Technical University, May 2015.

[8] Samavati R., Abdullah N., Tahmasbi Nowtarki K., Hussain S. A., and Awang Biak D. R., "Rheological and fluid loss properties of water-based drilling mud containing hcl-modified fufu as a fluid loss control agent," International Journal of ChemicalEngineering and Applications, vol. 5, no. 6, Dec 2014. 